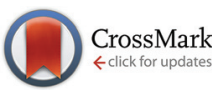

Cite this: Dalton Trans., 2014, 43, 18117

\title{
Exceptionally efficient catalytic hydrodechlorination of persistent organic pollutants: application of new sterically shielded palladium carbene complexes $\dagger$
}

\author{
Vagiz Sh. Saberov, ${ }^{a}$ Daniel A. Evans, ${ }^{b}$ Nikolai I. Korotkikh, ${ }^{\star a}$ Alan H. Cowley, ${ }^{\text {b }}$ \\ Tatyana M. Pekhtereva, ${ }^{a}$ Anatolii F. Popov ${ }^{a}$ and Oles P. Shvaika ${ }^{a}$
}

\begin{abstract}
A new sterically shielded carbene with branched aromatic substituents (9a) and two palladium halogenide complexes $(\mathbf{1} \mathbf{1} \mathbf{a}, \mathbf{b})$ have been prepared. The single crystal X-ray structures of free carbene $\mathbf{9 a}$ and palladium carbene complexes $\mathbf{1 0 b}$ and $11 \mathrm{a}$ were determined. Very high catalytic efficiencies were evident for the sterically shielded palladium carbene complexes $\mathbf{1 0 b}$ and $\mathbf{1 1} \mathbf{a}, \mathbf{b}$ when the latter complexes were employed as catalysts for hydrodechlorination of the chloroarenes $p$-dichlorobenzene and hexachlorobenzene. When optimized, the foregoing approach is significantly more effective than those of currently known transition metal carbene complexes. The most active catalysts were found to be the monocarbene complexes of palladium chloride and iodide, both of which feature highly branched aromatic substituents $(11 a, b)$.
\end{abstract}

Received 22nd September 2014, Accepted 20th October 2014

DOI: $10.1039 / c 4 d t 02908 a$

www.rsc.org/dalton
Several approaches have been developed for haloarene detoxification. Well established methods include combustion at high temperatures, oxidation in supercritical water, catalytic reduction with hydrogen, reduction by metals or nanometals, biodegradation, and microwave techniques. ${ }^{2-4}$ Among the foregoing methods, catalytic hydrodehalogenation offers the most promise as a cost effective solution for the neutralization of toxic POPs.

Several transition metal carbene complexes have been shown to be active with respect to hydrodehalogenation processes. In particular, palladium carbene complexes are well known to be suitable catalysts for the foregoing reactions. As an example, Nolan et al. demonstrated that an in situ generated palladium carbene catalyst based on $\operatorname{Pd}(\mathrm{dba})_{2}$, potassium methoxide, and various imidazolium salts resulted in high yields of hydrodehalogenation products upon reaction in dioxane solution at $100{ }^{\circ} \mathrm{C}$ (TON up to $28-50$, TOF up to 28-50 $\left.\mathrm{h}^{-1}\right)$. $^{5}$

As described in subsequent publications by Nolan et al., complex 1 (Fig. 1) was found to exhibit moderate catalytic efficiencies for the reactions of chlorobenzene at ambient temperature (TON 100, TOF $200 \mathrm{~h}^{-1}$ ). ${ }^{6}$ Moreover, complex 2 was shown to be active for the hydrodehalogenation of p-dichlorobenzene at $60{ }^{\circ} \mathrm{C}\left(\right.$ TON 194 , TOF $\left.111 \mathrm{~h}^{-1}\right) .^{7}$ Interestingly, when microwave assistance was employed for the reaction with complex 2 , an even higher rate of reaction could be achieved at $120{ }^{\circ} \mathrm{C}$. Using the latter approach, virtually quantitative yields for the hydrodechlorination of $p$-chlorotoluene 

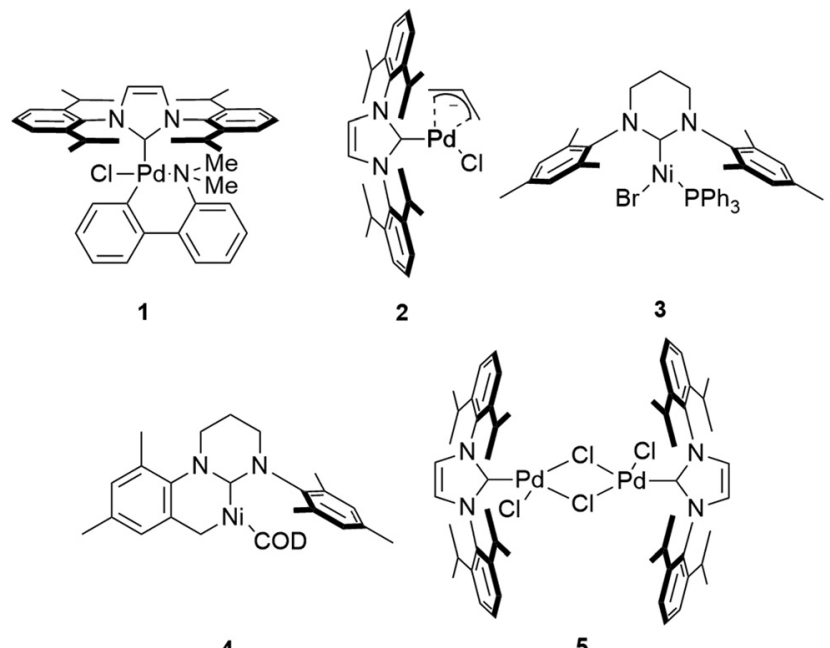

Fig. 1 Palladium and nickel carbene catalysts used for hydrodehalogenation reactions.

and $p$-dichlorobenzene can be achieved in only $2 \mathrm{~min}$ (TON 4000, TOF $120000 \mathrm{~h}^{-1} p$-chlorotoluene; TON 3800, TOF $114000 \mathrm{~h}^{-1} p$-dichlorobenzene). ${ }^{7}$

In addition to the three palladium carbene complexes discussed above, two nickel(I) complexes (Fig. 1) have also been examined as potential catalysts for hydrodehalogenation processes. Unfortunately, however, the nickel(I) complex 3 proved to be ineffective for both the hydrodebromination of $p$-bromofluorobenzene and also for the hydrodechlorination of $p$-chlorofluorobenzene, both of which are activated haloarenes (TON 15-22 and TOF $4-44 \mathrm{~h}^{-1}$ at $\left.25^{\circ} \mathrm{C}\right) .{ }^{8}$ Interestingly, however, the nickel(I) complex 4 was found to be active for the hydrodefluorination of fluorobenzenes. ${ }^{9}$ Taken collectively, complexes 1-4 were found to exhibit inadequate catalytic activities for the intended reactions.
Currently, the highest efficiency for the hydrodehalogenation of polyhalogenated arenes was obtained by using the dichloro-bridged dinuclear palladium carbene complex 5 that is displayed in Fig. $1 .^{10}$ This catalyst proved to be highly active for the hydrodehalogenation of either 1,2,4,5-tetrachlorobenzene or 2,2',3,3'-tetrachlorobiphenyl in isopropanol solution at $80{ }^{\circ} \mathrm{C}$ (TON 19650 , TOF $819 \mathrm{~h}^{-1}$ and TON 10000 , TOF $417 \mathrm{~h}^{-1}$, respectively). ${ }^{10}$

As evident from Fig. 1, the existence of steric hindrance adjacent to a carbenic carbon atom plays an important role with respect to the reactivities of carbenes. With the overall objective of developing more efficient catalysts for use in the environmentally important haloarene hydrodehalogenation reaction, the present work is focused on the development of new highly sterically shielded palladium carbene complexes.

\section{Results and discussion}

Syntheses of the stable, sterically shielded carbene 9a and palladium carbene complexes $10 \mathrm{~b}$ and 11a,b

The sterically shielded stable carbene 9a that features branched aromatic N-substituents was synthesized in four steps as outlined in Scheme 1. First, the sterically hindered 2,6-disubstituted aniline $\mathbf{6 a}$ was prepared by treatment of 4-ethylaniline with benzhydrol in the presence of $\mathrm{ZnCl}_{2}$ and concentrated aqueous $\mathrm{HCl}$. The subsequent reaction of the bulky aniline 6a with glyoxal in $n$-propanol solution in the presence of formic acid resulted in the formation of the corresponding diimine $7 \mathrm{a}$. In the next step, cyclization of the diimine 7a was accomplished by treatment with paraformaldehyde in the presence of $\mathrm{ZnCl}_{2}$ and concentrated aqueous $\mathrm{HCl}$, thereby forming the 1,3-diarylimidazolium salt 8a. Finally, treatment of the imidazolium salt $\mathbf{8 a}$ with $\mathrm{NaH}$ in THF solution afforded the free sterically shielded stable carbene $\mathbf{9 a}$ (see $\mathrm{ESI} \dagger$ ).
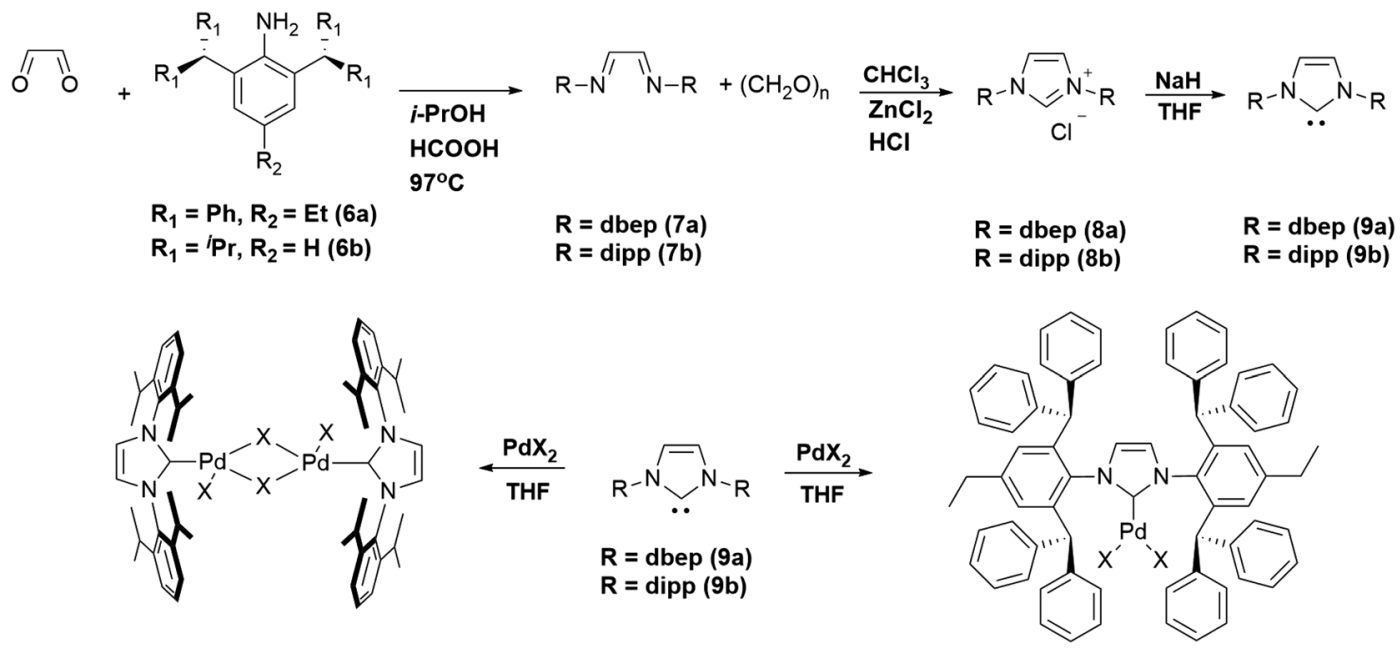

$10 \mathrm{a}, \mathrm{X}=\mathrm{Cl}$

$10 b, x=1$

11a, $X=C I$

$11 b, X=I$

Scheme 1 Syntheses of sterically shielded carbenes and their respective palladium complexes (dbep = 2,6-dibenzhydryl-4-ethylphenyl). 
In principle, the procedure that was employed for the synthesis of the imidazolium salt $\mathbf{8 a}$ is similar to that described by Marko et al. ${ }^{11}$ The known carbene $9 \mathbf{b}$ was generated from the imidazolium salt $\mathbf{8 b}$ via reaction with potassium tert-butoxide in THF solution. The subsequent reactions of the foregoing carbenes with palladium(II) chloride or palladium(II) iodide were carried out using a 1:1 molar ratio in THF solution at room temperature according to the literature procedure. ${ }^{12}$ The outcomes of these reactions were found to be dependent on the steric demands of the nitrogen substituents. On the one hand, the reaction of the more bulky dbep substituted carbene 9a with palladium halogenides afforded the mononuclear carbene complexes 11a,b. On the other hand, treatment of the less bulky dipp-substituted carbene $9 \mathbf{b}$ with $\mathrm{PdI}_{2}$ resulted in the formation of the diiodo-bridged dinuclear palladium carbene complex 10b, and is reminiscent of the corresponding reaction with $\mathrm{PdCl}_{2}{ }^{12}$

\section{Characterization of $6 \mathrm{a}-11 \mathrm{~b}$}

Compounds $\mathbf{6 a - 1 1 b}$ were characterized by means of ${ }^{1} \mathrm{H}$ and ${ }^{13} \mathrm{C}$ NMR spectroscopy and their compositions were established on the basis of elemental analyses. The crystal structures of $\mathbf{9 a}, \mathbf{1 0 b}$, and 11a were determined by single crystal $\mathrm{X}$-ray diffraction (see ESI $\dagger$ ).

\section{Single crystal X-ray diffraction studies}

Colorless single crystals of the free carbene 9a were grown by slow evaporation of a benzene solution of $9 \mathbf{a}$ and subsequently examined by X-ray diffraction. The free carbene 9a crystallized in the $P 2 / c$ space group of the monoclinic crystal system with two disordered benzene solvent molecules in the asymmetric unit. The crystal structure of $\mathbf{9 a}$, which is displayed in Fig. 2, features a planar $\mathrm{C}(1)-\mathrm{N}(1)-\mathrm{C}(2)-\mathrm{C}(3)-\mathrm{N}(2)$ five-membered ring that is akin to those found for the majority of imidazol-2ylidene rings. The plane of the central imidazol-2-ylidene moiety is oriented in an almost orthogonal fashion with respect to the planes of the flanking aryl substituents $\left(86.24^{\circ}\right.$ and $87.97^{\circ}$ ). The bond angle at the carbene carbon atom is
Table 1 Selected bond lengths ( $\AA$ ) for $9 a, 10 b$, and 11a

\begin{tabular}{llll}
\hline Bond & $\mathbf{9 a}(\AA)$ & $\mathbf{1 0 b}(\AA)$ & $\mathbf{1 1 a}(\AA)$ \\
\hline $\mathrm{C}(1)-\mathrm{N}(1)$ & $1.364(4)$ & $1.347(6)$ & $1.359(3)$ \\
$\mathrm{C}(1)-\mathrm{N}(2)$ & $1.368(4)$ & $1.352(6)$ & $1.359(3)$ \\
$\mathrm{C}(1)-\mathrm{N}(1 \mathrm{a})$ & & & - \\
$\mathrm{C}(2)-\mathrm{C}(3)$ & $1.327(5)$ & $1.332(7)$ & $1.340(5)$ \\
$\mathrm{C}(2)-\mathrm{C}(2 \mathrm{a})$ & & & $1.394(3)$ \\
$\mathrm{C}(2)-\mathrm{N}(1)$ & $1.387(4)$ & $1.378(6)$ & - \\
$\mathrm{C}(3)-\mathrm{N}(2)$ & $1.381(4)$ & $1.387(6)$ & $1.961(4)$ \\
$\mathrm{C}(1)-\mathrm{Pd}(1)$ & - & $1.985(4)$ &
\end{tabular}

101.5(2) ${ }^{\circ}$, and the existence of high bond orders of 1.61-1.63 for the $\mathrm{C}(1)-\mathrm{N}(1)$ and $\mathrm{C}(1)-\mathrm{N}(2)$ bonds and 1.50-1.53 for the $\mathrm{C}(2)-\mathrm{N}(1)$ and $\mathrm{C}(3)-\mathrm{N}(2)$ bonds imply a substantial amount of delocalization within the carbene ring structure. Interestingly, the $\mathrm{C}(2)-\mathrm{C}(3)$ bond (Table 1 ) features a noticeably shortened bond length of 1.327(5) A and a bond order of 2.051.

Dark red single crystals of $\mathbf{1 0 b}$ were grown by slow vapor diffusion of hexanes into a chloroform solution of this compound. As displayed in Fig. 2, complex 10b possesses a diiodo-bridged dinuclear structure of the overall composition $\left(\mathrm{LPdI}_{2}\right)_{2}$.

Complex $10 \mathrm{~b}$ crystallizes in the $P \overline{1}$ space group of the triclinic crystal system and features two diiodo-bridged dinuclear structures in the asymmetric unit. Interestingly, complex 10b exhibits a distorted $\mathrm{I}(2)-\mathrm{Pd}(1)-\mathrm{I}(3)-\mathrm{Pd}(2)$ four-membered ring structure with a torsion angle of $157.522(16)^{\circ}$. Furthermore, the planes of the imidazolium and adjacent flanking dipp groups are oriented in an essentially orthogonal manner $\left(82.0^{\circ}\right.$ and $86.5^{\circ}$ ).

Yellow single crystals of the palladium carbene complex 11a were grown by slow evaporation of an acetonitrile solution and examined by single crystal X-ray diffraction. The palladium carbene complex 11a crystallized in the $I 2 / a$ space group of the monoclinic crystal system. Complex 11a also features a twofold rotational axis that bisects the complex along the $\mathrm{C}(1)-$ $\operatorname{Pd}(1)-\mathrm{N}(2)$ bond, hence only half of the complex is apparent in the asymmetric unit. In contrast to $\mathbf{1 0 b}$, complex 11a possesses
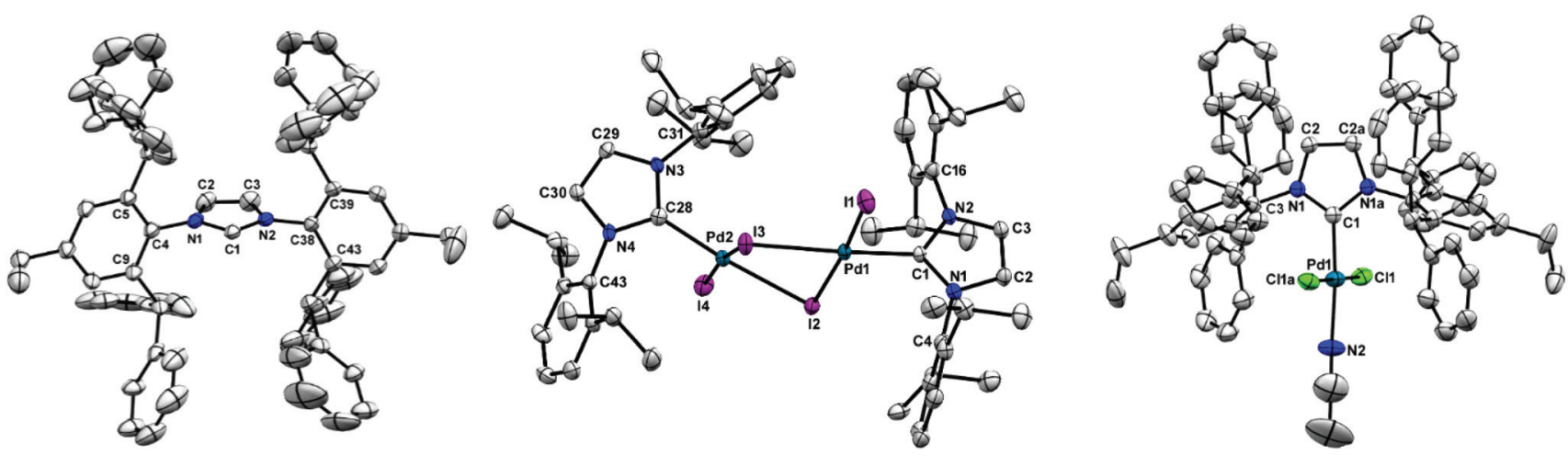

Fig. 2 POV-Ray diagrams of the free carbene 9a (left) and palladium carbene complexes 10b (center) and 11a (right) with thermal ellipsoids displayed at $50 \%$ probability. Compound 9 a crystallized with two disordered benzene solvent molecules and complex $10 \mathrm{~b}$ crystallized with two dinuclear species in the asymmetric unit, only one of which is displayed above. Complex 11a crystallized with two disordered acetonitrile solvent molecules. All solvent molecules and hydrogen atoms have been omitted for clarity. 
a mononuclear structure. The bond angle at the carbene carbon $\left(105.4(3)^{\circ}\right)$ is significantly larger than that exhibited by the free carbene 9a $\left(101.5(2)^{\circ}\right)$. Moreover, the imidazol2-ylidene bond lengths are similar to those measured for the free carbene 9a (Table 1). Furthermore, the angle between the plane of the imidazol-2-ylidene ring and that of the flanking aryl substituent is more acute in 11a $\left(71.68^{\circ}\right)$ than that in the free carbene 9a $\left(86.24^{\circ}\right.$ and $\left.87.97^{\circ}\right)$. In summary, palladium complexes 10b and 11a both adopt square planar geometries and feature strong $\mathrm{Pd}-\mathrm{C}$ bonds and noticeably shortened $\mathrm{Pd}-\mathrm{Cl}$ and Pd-I bonds (ESI $\dagger$ ).

\section{Catalytic studies}

The hydrodechlorination test reactions were performed by heating each reaction mixture containing the haloarene with potassium or sodium isopropoxide. The latter compounds had been generated from potassium or sodium tert-butoxide (or hydroxide) in the presence of the palladium catalyst in isopropanol solution at $80^{\circ} \mathrm{C}$. Each percent conversion was based on one chlorine atom and calculated according to the masses of the sodium or potassium chlorides. The most efficient catalysis trials were examined by means of gas chromatography. The catalytic efficiencies were estimated by using the TON and TOF values (the general procedure is described in the ESI $\dagger$ ). A summary of the catalytic efficiencies of carbene complexes 10a, b and 11a,b with respect to the model compound $p$-dichlorobenzene and a variety of bases is presented in Table 2 .

As evident from Table 2, the hydrodechlorination of p-dichlorobenzene with potassium tert-butoxide in the presence of catalysts $\mathbf{1 0 a}, \mathbf{b}$ and $\mathbf{1 1 a}, \mathbf{b}$ proceeded very efficiently.
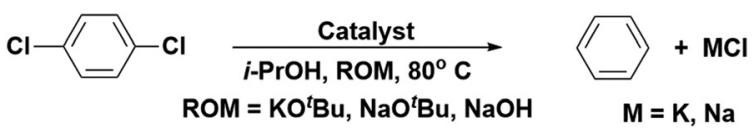

Table 2 Catalytic efficiencies of palladium catalysts $10 a, b$ and $11 a, b$ for the hydrodechlorination of $p$-dichlorobenzene

\begin{tabular}{|c|c|c|c|c|c|c|}
\hline Cat. & $\begin{array}{l}\text { Cat. loading } \\
(\mathrm{mol} \%)\end{array}$ & $\begin{array}{l}\text { Time } \\
\text { (h) }\end{array}$ & $\begin{array}{l}\text { Conver. } \\
(\%)\end{array}$ & $\begin{array}{l}\text { TON } \\
(\text { per } 1 \mathrm{Cl})\end{array}$ & $\begin{array}{l}\text { TOF } \\
\left(\mathrm{h}^{-1}\right)\end{array}$ & ROM \\
\hline $10 a$ & 0.01 & 8 & 63 & 12600 & 1560 & $\mathrm{KO}^{t} \mathrm{Bu}$ \\
\hline 10a & 0.01 & 24 & 88 & 17600 & 734 & $\mathrm{KO}^{t} \mathrm{Bu}$ \\
\hline $10 a$ & 0.01 & 24 & 32 & 6400 & 266 & $\mathrm{NaO}^{t} \mathrm{Bu}$ \\
\hline $10 a$ & 0.01 & 24 & 96 & 19200 & 800 & $\mathrm{NaOH}$ \\
\hline 10a & 0.001 & 24 & 5 & 10000 & 416 & $\mathrm{NaOH}$ \\
\hline $10 \mathrm{~b}$ & 0.01 & 24 & 100 & 20000 & 834 & $\mathrm{KO}^{t} \mathrm{Bu}$ \\
\hline 10b & 0.001 & 24 & 22 & 44000 & 1830 & $\mathrm{KO}^{t} \mathrm{Bu}$ \\
\hline $10 \mathrm{~b}$ & 0.01 & 24 & 100 & 20000 & 834 & $\mathrm{NaO}^{t} \mathrm{Bu}$ \\
\hline $10 b$ & 0.001 & 24 & 23 & 46000 & 1916 & $\mathrm{NaO}^{t} \mathrm{Bu}$ \\
\hline $10 b^{a}$ & 0.001 & 24 & 30 & 60000 & 2500 & $\mathrm{NaO}^{t} \mathrm{Bu}$ \\
\hline $10 b$ & 0.01 & 24 & 100 & 20000 & 834 & $\mathrm{NaOH}$ \\
\hline $10 b$ & 0.001 & 24 & 21 & 42000 & 1750 & $\mathrm{NaOH}$ \\
\hline $10 b^{a}$ & 0.001 & 24 & 30 & 60000 & 2500 & $\mathrm{NaOH}$ \\
\hline $11 a$ & 0.001 & 24 & 70 & 140000 & 5833 & $\mathrm{KO}^{t} \mathrm{Bu}$ \\
\hline $11 b$ & 0.001 & 24 & 90 & 180000 & 7500 & $\mathrm{KOtBu}$ \\
\hline
\end{tabular}

${ }^{a}$ The reaction was run in the presence of $1 \% \mathrm{LiO}^{t} \mathrm{Bu}$.
The catalytic efficiencies of the dipp-substituted complexes 10a,b were examined initially. The known complex $\mathbf{1 0 a}^{13}$ exhibited high TON and TOF values for the hydrodechlorination of $p$-dichlorobenzene (TON 17600, TOF $1560 \mathrm{~h}^{-1}$ ). The catalytic efficiency increased when the known chloride complex 10a had been replaced by the palladium iodide complex 10b (TON 44000, TOF $1830 \mathrm{~h}^{-1}$ ). Upon changing the base that had been used in the reaction with sodium tert-butoxide (Table 2), a similar level of efficiency was evident for complex 10b (TON 46000 , TOF $1916 \mathrm{~h}^{-1}$ ). However, the efficiency of $\mathbf{1 0 b}$ significantly exceeded that observed for the palladium chloride complex 10a (TON 6400, TOF $266 \mathrm{~h}^{-1}$ ).

As the next step, the hydrodechlorination reactions of $\mathbf{1 0 a}, \mathbf{b}$ and 11a,b were carried out in the presence of sodium hydroxide in an isopropanol solution. From the standpoint of haloarene neutralization, the use of the inexpensive base sodium hydroxide is of particularly importance with regard to applications in real world technology. It was found that the known complex 10a was somewhat more effective for the reaction with sodium hydroxide (TON 19200 , TOF $800 \mathrm{~h}^{-1}$ ), than with either potassium or sodium tert-butoxide (TON 17600 , TOF $734 \mathrm{~h}^{-1}$ and TON 6400, TOF $266 \mathrm{~h}^{-1}$, respectively). Moreover, complex 10b (TON 42000 , TOF $1750 \mathrm{~h}^{-1}$ ) was significantly more effective than 10a in the presence of $\mathrm{NaOH}$.

Overall, the efficiency of $\mathbf{1 0 b}$ is somewhat independent of the identity of the bases that were tested for use in this reaction. However, upon using $0.001 \mathrm{~mol} \%$ of 10a, a decrease in catalytic efficiency became evident (TON 10000 , TOF $416 \mathrm{~h}^{-1}$ vs. 19200 and $800 \mathrm{~h}^{-1}$, respectively with $0.01 \mathrm{~mol} \%$ of catalyst 10a). The foregoing decrease in efficiency is possibly due to the equilibrium reaction of $\mathrm{i}-\mathrm{PrOH}+\mathrm{NaOH} \rightleftarrows \mathrm{i}-\mathrm{PrONa}+\mathrm{H}_{2} \mathrm{O}$ that generates water and thereby deactivates this complex, particularly at lower catalyst concentrations. Interestingly, the catalytic efficiency of complex $\mathbf{1 0 b}$ increased in the presence of a small quantity of lithium tert-butoxide (1 mol\%) (TON 60000 , TOF $2500 \mathrm{~h}^{-1}$ vs. 42000 and $1750 \mathrm{~h}^{-1}$ respectively for complex $10 \mathrm{~b}$ without the additive).

The sterically shielded palladium carbene complexes with branched aromatic N-substituents, 11a,b, proved to be significantly more efficient than $\mathbf{1 0 a}, \mathbf{b}$. The catalytic trials that were carried out using 11a,b with potassium tert-butoxide (Table 2) exhibited excellent efficiencies and increased TON values of 140000 and 180000 and TOF values of $5833 \mathrm{~h}^{-1}$ and $7500 \mathrm{~h}^{-1}$, respectively.

The most effective catalysts were found to be $\mathbf{1 0 b}$ and $\mathbf{1 1 a}, \mathbf{b}$, as determined on the basis of the model hydrodechlorination reactions with $p$-dichlorobenzene. Subsequently, 10b and 11a,b were examined for the hydrodechlorination of the known POP hexachlorobenzene. The pertinent catalytic data obtained in this study can be found in Table 3 . The catalysts $10 \mathbf{b}$ and 11a,b displayed excellent efficiencies for the hydrodechlorination of hexachlorobenzene with TON and TOF values that ranged from 88 000-318 000 and 3667-13 $350 \mathrm{~h}^{-1}$, respectively. Reactions that resulted in $100 \%$ conversion, as estimated by mass analysis of the metal halide precipitates, were confirmed by means 


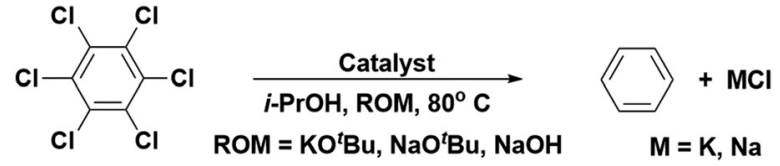

Table 3 Catalytic efficiencies of palladium catalysts $10 a, b$ and $11 a, b$ for the hydrodechlorination of hexachlorobenzene

\begin{tabular}{lllrlrl}
\hline Cat. & $\begin{array}{l}\text { Cat. load. } \\
(\text { mol\% })\end{array}$ & $\begin{array}{l}\text { Time } \\
(\mathrm{h})\end{array}$ & \multicolumn{1}{c}{$\begin{array}{l}\text { Conv. } \\
(\%)\end{array}$} & $\begin{array}{l}\text { TON } \\
(\text { per } 1 \mathrm{Cl})\end{array}$ & $\begin{array}{l}\text { TOF } \\
\left(\mathrm{h}^{-1}\right)\end{array}$ & $\mathrm{ROM}$ \\
\hline 10b & 0.01 & 24 & 100 & 60000 & 2500 & $\mathrm{KO}^{t} \mathrm{Bu}$ \\
10b & 0.01 & 24 & 66 & 39600 & 1650 & $\mathrm{NaOH}$ \\
10b & 0.003 & 24 & 44 & 88000 & 3667 & $\mathrm{KO}^{t} \mathrm{Bu}$ \\
11a & 0.001 & 24 & 35 & 210000 & 8750 & $\mathrm{KO}^{t} \mathrm{Bu}$ \\
11a & 0.005 & 24 & 100 & 120000 & 5000 & $\mathrm{KO}^{t} \mathrm{Bu}$ \\
11b & 0.001 & 24 & 53 & 318000 & 13350 & $\mathrm{KO}^{t} \mathrm{Bu}$ \\
11b & 0.004 & 24 & 100 & 150000 & 6250 & $\mathrm{KO}^{t} \mathrm{Bu}$
\end{tabular}

of gas chromatography, which did not detect any intermediates or initial haloarenes.

To the best of our knowledge, the catalytic efficiencies that were determined for complexes 11a,b represent the highest efficiencies reported to date for the hydrodehalogenation of polyhaloarenes (TON 210 000-318 000, TOF 8750-13 $350 \mathrm{~h}^{-1}$ ). Quantitative conversion per chlorine atom was achieved after $24 \mathrm{~h}$ with catalyst concentrations of $0.004-0.005 \mathrm{~mol} \%$. When comparing the efficiencies of $\mathbf{1 0 b}$ and $\mathbf{1 1 a}, \mathbf{b}$ for the hydrodehalogenation of hexachlorobenzene, the best known catalyst (10a) was found to exhibit lower catalytic efficiencies for the reactions involving 1,2,4,5-tetrachlorobenzene (TON 19700, TOF $821 \mathrm{~h}^{-1}$ ), 2,2',3,3'-tetrachlorobiphenyl (TON 10000 , TOF $420 \mathrm{~h}^{-1}$ ), and decachlorobiphenyl (TON 1000, TOF $42 \mathrm{~h}^{-1}$ ). ${ }^{10}$ The best catalysts, 11a,b, exceeded the maximum level of efficiency for 10a by a factor of 10-16 times. Furthermore, catalysts $11 \mathrm{a}, \mathbf{b}$ required only a $0.001-0.005 \mathrm{~mol}$ percent concentration in order to function efficiently as compared with 10a which is only active in the concentration range of 0.01-0.04 mol percent.

The proposed mechanism for the haloarene hydrodehalogenation reaction (Scheme 2) ${ }^{14,15}$ involves initial reaction of the pre-catalyst $\mathbf{A}$ with potassium isopropoxide (that was generated from potassium or sodium tert-butoxide or hydroxide) to form the alkoxide derivative B. In the next step, the latter complex underwent $\beta$-hydride elimination, thereby releasing acetone and generating the hydridic palladium species $\mathbf{C}$. The subsequent reaction of the hydridic species $\mathbf{C}$ with potassium tert-butoxide resulted in formation of the active palladium( 0 ) complex D. Subsequent activation of the $\mathrm{C}-\mathrm{Cl}$ bond in the haloarene compound $\mathbf{E}$ by complex $\mathbf{D}$ resulted in oxidative addition and the formation of complex $\mathbf{F}$.

The reaction of complex $\mathbf{F}$ with potassium isopropoxide afforded the alkoxide complex G. Following this, an analogous $\beta$-hydride elimination step occurred, thereby generating the hydridic species H. Finally, reductive elimination resulted in formation of the protonated arene compound and regeneration of the active catalyst palladium(0) complex $\mathbf{D}$.

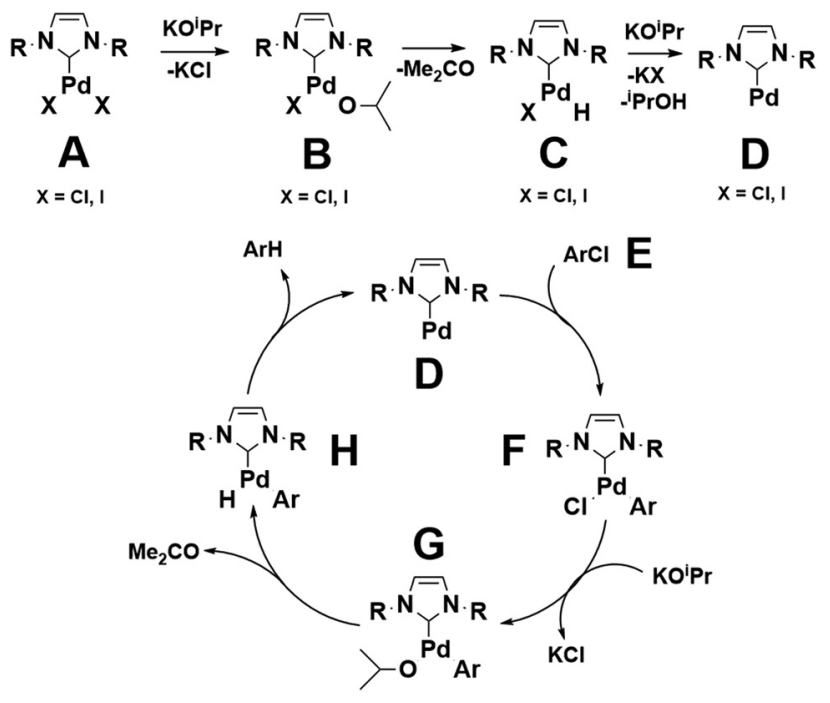

Scheme 2 Proposed mechanism for haloarene hydrodehalogenation.

Based on previous studies of related sterically shielded 1,2,4-triazol-5-ylidene systems ${ }^{16}{ }^{16}$ an important stage in the foregoing process may involve interaction of the initial precatalyst $\mathbf{A}$ with the metal isopropoxide. This reaction should be more facile for the iodide complexes than for the corresponding chloride analogues. As might be expected, the stabilities of these complexes depend on the extent of steric congestion.

In summary, it is noteworthy that highest catalytic activities for hydrodehalogenation to date have been achieved by the development of new palladium complexes with sterically shielded 1,3-diarylimidazol-2-ylidene ligands that feature two bulky, branched aromatic N-substituents, namely 11a,b. A plausible reason for the dramatic increases in catalytic activities that were observed for the sterically shielded carbene complexes 11a,b (in comparison with those of their dipp substituted counterparts 10a,b) could be attributed to stabilization of the $\operatorname{Pd}(0)$ complex $\mathbf{D}$ on account of the steric protection afforded by the bulky carbene ligand. Another important contributor to this enhancement of catalytic efficiency is the presence of iodide as the second ligand $(\mathbf{1 0 b}, \mathbf{1 1 b})$ (chloride ligands typically exhibit lower catalytic efficiencies than those of iodide-containing complexes). In summary, the excellent activities that were observed for 11a,b at very low mol percent catalyst loadings imply that $\mathbf{1 1 a , b}$ represent a realistic and efficient technology for the remediation of haloarene POPs.

\section{Conclusions}

A new sterically shielded stable carbene of the imidazole series with highly branched aromatic N-substituents (9a) has been synthesized and structurally authenticated by means of a single crystal X-ray diffraction study. The X-ray crystal structures of the palladium carbene complexes 10b and 11a were also determined. It was discovered that complexes $\mathbf{1 0 b}$ and 
11a,b serve as highly efficient catalysts for the hydrodehalogenation of both hexachlorobenzene and p-dichlorobenzene. Moreover, each catalyst proved to be effective at very low mol percent catalyst loadings. Furthermore, the catalytic efficiencies of complexes $\mathbf{1 0 b}$ and $\mathbf{1 1 a}, \mathbf{b}$ were found to be significantly superior for the hydrodehalogenation reaction of hexachlorobenzene than those of $p$-dichlorobenzene. In summary, complexes 11a,b represent excellent candidates for the effective waste management of haloarene POPs. Finally, the sterically shielded imidazol-2-ylidene palladium iodide complex 11b was found to exhibit the highest efficiency for the hydrodehalogenation reaction that has been reported to date and significantly exceeds the efficiencies of the current literature values of the known complex 10a and its iodide analogue $\mathbf{1 0 b}$.

\section{Acknowledgements}

We thank the Ukrainian Academy of Sciences for financial support (grant no. 140, 28.03.2013), and the generous financial support provided by the Robert A. Welch Foundation (grant F-0003) (A.H.C.).

\section{References}

1 T. I. Gorbunov, V. I. Saloutin and O. N. Chupakhin, Russ. Chem. Rev., 2010, 79, 565 (rus).

2 F. Alonso, I. Beletskaya and M. Yus, Chem. Rev., 2002, 102, 4009-4091.

3 C. L. Geiger, K. Carvalho-Knighton, S. Novaes-Card, P. Maloney and R. DeVor, in Environmental Applications of Nanoscale and Microscale Reactive Metal Particles/ACS Symposium Series, American Chemical Society, Washington, DC, 2010.

4 W. M. Czaplik, S. Grupe, M. Mayer and A. J. von Wangelin, Chem. Commun., 2010, 46, 6350.
5 M. S. Viciu, G. A. Grasa and S. P. Nolan, Organometallics, 2001, 20, 3607.

6 O. Navarro, N. Marion, Y. Oonishi, R. A. Kelly and S. P. Nolan, J. Org. Chem., 2006, 71, 685.

7 O. Navarro, H. Kaur, P. Mahjoor and S. P. Nolan, J. Org. Chem., 2004, 69, 3173.

8 C. J. E. Davies, M. J. Page, C. E. Ellul, M. F. Mahon and M. K. Whittlesey, Chem. Commun., 2010, 46, 5151.

9 S. Kuhl, R. Schneider and Y. Fort, Adv. Synth. Catal., 2003, $345,341$.

10 S. Akzinnay, F. Bisaro and C. S. J. Cazin, Chem. Commun., 2009, 5752 .

11 G. Berthon-Gelloz, M. A. Siegler, A. L. Spek, B. Tinant, J. N. H. Reek and I. E. Marko, Dalton Trans., 2010, 39, 1444.

12 N. I. Korotkikh, V. Sh. Saberov, A. V. Kiselev, N. V. Glinyanaya, K. A. Marichev, T. M. Pekhtereva, G. V. Dudarenko, N. A. Bumagin and O. P. Shvaika, Chem. Heterocycl. Compd., 2012, 47, 1551.

13 M. S. Viciu, R. M. Kissling, E. D. Stevens and S. P. Nolan, Org. Lett., 2002, 4, 2229.

14 (a) D. Enders, O. Niemeier and A. Henseler, Chem. Rev., 2007, 107, 5606; (b) N-Heterocyclic Carbenes in Synthesis, ed. S. P. Nolan, Wiley VCH Verlag GmbH \& Co KgaA, Weinheim, 2006, p. 68; (c) J. Izquierdo, G. E. Hutson, D. T. Cohen and K. A. Scheidt, Angew. Chem., Int. Ed., 2012, 51, 11686; (d) M. J. Fuchter, Chem. - Eur. J., 2010, 16, 12286; (e) P.-C. Chiang and J. Y. W. Bode, in RSC Catalysis Series No. 6: N-Heterocyclic Carbenes: From Laboratory Curiosities to Efficient Synthetic Tools, ed. S. Diez-Gonzalez. Royal Society of Chemistry, 2013, ch. 14, p. 399.

15 N. I. Korotkikh and O. P. Shvaika, Carbene and carbene complex catalysis of organic reactions, Donetsk, DonNU, 2013, 372 p. (ukr.).

16 N. V. Glinyanaya, V. Sh. Saberov, N. I. Korotkikh, A. H. Cowley, R. R. Butorac, D. A. Evans, T. M. Pekhtereva, A. F. Popov and O. P. Shvaika, Dalton Trans., 2014, 43, 16227. 